\title{
REFERENCES
}

1 García Frías, J. (1970). The revision of the Rules. This Journal, 23, 71.

2 Clissold, P. C. H. (1969). Why the Rules need changing. This Journal, 22, 286.

3 Thompson, P. A. (1970). Revised Rules for preventing collisions at sea. This Journal, 23, 81 .

4 Dickson, A. F. (1969). Changing the Collision Regulations. This Journal, 22, 447.

\section{A Note on the Use of DCF for Marine Project Evaluation}

\author{
J. S. McKenzie \\ (Marine \& General Computer Consultancy (I.O.M.) Ltd.)
}

King's observation ${ }^{1}$ that a false impression could be gained from long-term savings that do not take account of the time value of money is no doubt true if all aspects and factors of comparative projects are taken into account. However, he must think readers a little naive if he offers his Fig. 3 as a full interpretation of the possible savings from installing the various levels of shipborne automation explored in my recent article. ${ }^{2}$ An examination of Section 8 (Cost Equations) will show that the DCF technique was deliberately discarded in order to simplify the argument. In fact, there was an additional note-deleted by the Editor through lack of space-which observed that the appraisal could be based on the assumption that the discount rate was equal to the escalation rate of the savings occasioned by taking into account the rise in wages, victualling, \&c. over the equivalent project period.

Omission or no, DCF techniques should not be treated as superficially as King appears to do in his note. The improvement in NPV at various discount rates is quite meaningless unless related to the projected variation in the cash flows. The essence of DCF is the ability to consider such flows in detail and work on elements or vectors in the cost matrices; continually refining the estimates of fixed outgoings in year $i$ or the rate of advance of, say, wages in years $m$ to $n$. Looking again at Table III in 'Manning Reductions and the Cost of Navigation' we see that wages, both at the base level and for subsequent stages, would need to be assessed at one level of escalation, and the victualling and incidentals at others. Furthermore, each of the incidentals would need close examination to determine whether their escalation rates were compatible and could be generalized. Then attention would need to be directed to the maintenance of accommodation and equipment, as these certainly could not be considered equal. They would reflect different rates of wage increases and would need to take into account advances in technology over the period of the project.

It would seem that only when we look at direct capital investment, or the lack of it, could we afford to neglect a detailed study, but even here it was noted that the equipment costs for stage 4 were 'of an order' rather than specific. Where does that leave us when we turn to the question of whether DCF should be used ? Certainly when we have determined the appropriate rates of escalation and the correct time for payment or receipt of monies we are approaching a better 
position, but what about the quantification of operational benefits in the navigation sphere obtained from installing more sophisticated equipment? Fewer collisions, less strandings and a more efficient 'watch' can all be claimed for computer based systems, not to mention benefits accruing from better track maintenance and more efficient helm control, and these must be quantified.

As the developers of a sophisticated project evaluation computer package which uses DCF techniques, we at Marine \& General are very much aware of the use of NPV and internal rate of return calculations, but we feel that evaluation must be on the basis of a definitive project which looks carefully at all factors. Such a project is illustrated in one of our major studies on the economics of a shipboard computer, an extract from which has been published. ${ }^{3}$ The realities of implementation were imposed on the more philosophical approach of the Manning Reductions article now under discussion, and the project was analysed on the basis of implementation in stages with consequent capital outflow at specific times within the Io-year project period. To have gone into this detail in the Manning Reductions article would not only have complicated the argument, it would also have given a spurious accuracy to an otherwise incomplete project. What we require is more, and more accurate, data to be able to approach a position where we can use DCF techniques. At that happy time we may have a specific project to evaluate.

\section{REFEREN CES}

1 King, J. (1971). A note on manning reductions and navigation. This Journal, 24, 556.

2 McKenzie, J. S. (1971). Manning reductions and the cost of navigation. This Journal, 24, 123.

3 McKenzie, J. S. (1970). The economics of a shipborne computer, Shipbuilding \& Shipping Record, Vol. I 16, No. 4.

\section{'Manning Reductions and the Cost of Navigation'}

\section{P. T. Bingley}

AFTER studying Captain J. S. McKenzie's very interesting paper on the above subject (Journal 24, 174), and recognizing the need for an improvement in the safety of navigation, it would seem worthwhile considering whether safety could be improved while still reducing costs.

Using Captain McKenzie's assumed costs, and his Table III as a model, the accompanying table shows the costs and savings for two versions of an allofficer bridge manning scheme.

Stage X-Total seven officers. The Master would carry out his duties in the traditional way, with watchkeeping duties carried out by six officers, viz. two officers in each watch. The radio equipment is automated and under the supervision of the bridge watchkeepers. Compared with the base this saves $£_{40,000}$ over i 5 years. If the Master undertook some watchkeeping duties, a full time radio officer could be retained and a further $£ 25,000$ saved by not automating the radio equipment. 